
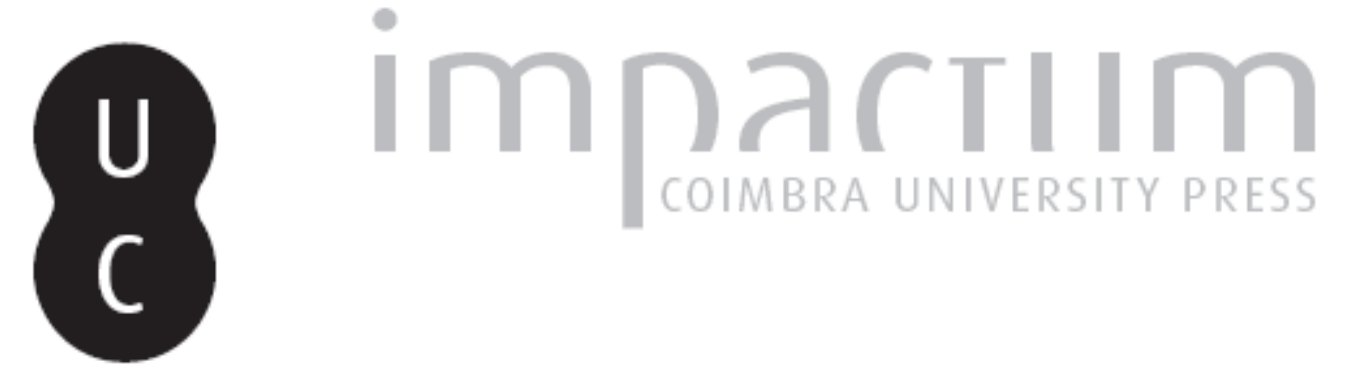

\title{
[Recensão a] López Mullor (A.), Las Cerámicas Romanas de Paredes Finas en Cataluña, Vol. I e II
}
Autor(es):
Nolen, Jeannette U. S.

Publicado por: Imprensa da Universidade de Coimbra

URL persistente:

URI:http://hdl.handle.net/10316.2/45519

DOI:

DOI:https://dx.doi.org/10.14195/1647-8657_31_14

Accessed : $\quad$ 26-Apr-2023 11:33:15

A navegação consulta e descarregamento dos títulos inseridos nas Bibliotecas Digitais UC Digitalis, UC Pombalina e UC Impactum, pressupõem a aceitação plena e sem reservas dos Termos e Condições de Uso destas Bibliotecas Digitais, disponíveis em https://digitalis.uc.pt/pt-pt/termos.

Conforme exposto nos referidos Termos e Condições de Uso, o descarregamento de títulos de acesso restrito requer uma licença válida de autorização devendo o utilizador aceder ao(s) documento(s) a partir de um endereço de IP da instituição detentora da supramencionada licença.

Ao utilizador é apenas permitido o descarregamento para uso pessoal, pelo que o emprego do(s) título(s) descarregado(s) para outro fim, designadamente comercial, carece de autorização do respetivo autor ou editor da obra.

Na medida em que todas as obras da UC Digitalis se encontram protegidas pelo Código do Direito de Autor e Direitos Conexos e demais legislação aplicável, toda a cópia, parcial ou total, deste documento, nos casos em que é legalmente admitida, deverá conter ou fazer-se acompanhar por este aviso.

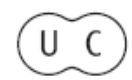


FACULDADE DE LETRAS

INSTITUTO DE ARQUEOLOGIA

\section{CONIMBRIGA}

VOLUME XXXI

,

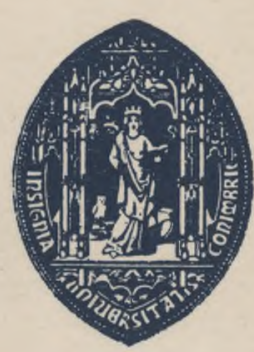

UNIVERSIDADE DE COIMBRA

1992 
López Mullor (A.), Las Cerámicas Romanas de Paredes Finas en Cataluña, Vol. I e II, 2- ed., Libros Pórticos, Zaragoza, 1990; pp. 691, est. 323 e mapas.

Puerta i López (C.), Baetulo, Ceràmica de Parets Fines, Monografies Badalonines 11, Badalona, 1989; pp. 91, est. 74.

O autor do primeiro volume, Alberto López Mullor, é professor da Universidad Autónoma de Barcelona, director das escavações de Ampúrias e colaborador tanto do museu Arqueológico de Barcelona como do Instituto de Prehistoria y Arqueología da Diputación de Barcelona. O presente livro é uma síntese da sua tese de doutoramento de 1989, publicado no ano seguinte, em 1990. Infelizmente, a investigação propriamente dita foi dada por encerrada no mês de Setembro de 1987, consequentemente, o material de «paredes finas» de várias escavações aqui apresentado, inclui apenas os achados estratigráficos até àquela data.

O outro volume tem a sua origem na tese de licenciatura de Carme Puerta i López. A autora publica toda a cerâmica de «paredes finas» das escavações de Badalone, tanto o material das escavações antigas, como aquele das mais recentes. O último constitui um lote de «paredes finas» de estratigrafía conhecida e cronologia documentada. Pena é que, para quem não percebe bem o Catalão, o livro tenha a grande desvantagem de estar escrito naquela língua.

Constituem dois estudos de especial interesse para os investigadores na Península, sobre «paredes finas» de estratigrafía e origem documentada na Catalunha em geral e de Badalona em especial. As mais importantes publicações sobre a cerâmica de «paredes finas» de estratigrafía até agora conhecida tratam de Albintimilium, Ostia, Cosa, Usk, Glanum, Conímbriga e das necrópoles de Farrobo e Aljustrel, no Baixo Alentejo $\left({ }^{x}\right)$. Os achados das primeiras três estações consistem, na sua quase totalidade, em peças de fabrico italiano ou gálico, os quais pouco valem para comparar com a produção peninsular, de longe mais frequentes em Portugal. Dos centros de Mérida e da Bética tivemos o prazer de publicar algumas peças provindas da necrópole de Santo André no vol. XX desta revista, aliás com cronologia muito restrita. Porém, de Conímbriga, das mencionadas necrópoles e entre as peças publicadas por Françoise Mayet no seu volume sobre as «paredes finas» da Península Ibérica e o resumo global de Ricci ( ${ }^{2}$ ), já dispomos de um corpus

(r) Lamboglia (N.), Gli scavi di Albintimilium e la cronologia della ceramica romana, I, Campagne di scavo 1938-1940, Bordighera, 1950; POHL(I.), «Ostia, Casa della pareti gialle, salone centrale. Scavo sotto il pavimento a mosaico», Notizie degli scavi di Antichità, Serie Vili, vol. XXIV, I, suppl., 1970, pp. 43-234; MOEVS (M. T. MARABINI), The Roman Thin Walled Pottery from Cosa (1948 -1954), Memoirs of the American Academy in Rome, voi. XXXII, Roma, 1973; GreENE (K.), The Pre-Flavian Fine Wares, Report on the Excavations at Usk, 1965-1976, Cardiff, 1979; BÉMONT (C), «Vases à Parois Fines de Glanum: Formes et Décors», Gallia, 34, fasc.1, 1976, pp. 237-278; Alarcão (J. de), Delgado (M.), MaYet (F.), Alarcáo (A. Moutinho) e Ponte (S. da), Fouilles de Conímbriga VI, Céramiques diverses et verres, Paris, 1976; ALARCÄO (J. de), «O espólio da necrópole luso-romana de Valdoca (Aljustrel)», Conímbriga, V, 1966, pp. 7-104. 
bastante vasto desta ceràmica com cronologia delimitada. O estudo de López Mullor, aliás, é posterior às últimas duas publicações mencionadas, tal como o de Carme Puerta i López, o que pode, nalguns casos, alterar as conclusões cronológicas nele avançadas.

A contribuição cronológica que o material de Baetulo pode trazer é, porém, limitada. A cidade teve uma existência muito restrita: fundada nos inícios do século I, alcançou o maior florescimento durante a época de Augusto até aos inícios dos Flávios; posteriormente, parece ter sido abandonada em grande parte (p. 15), de maneira que as conclusões sobre os inícios ou termo das formas nem sempre nos parecem legítimas. Sentimos esta hesitação especialmente porque os achados estratigráficos são poucos ou até raros $\mathrm{e}$ bem podiam representar um ligeiro revolvimento das camadas. Para basear raciocínios, precisamos de testemunhos bastante mais numerosos do que os que a autora nos oferece.

O estudo da cerâmica de «paredes finas» tem, nas últimas décadas, avançado muito quanto ao estabelecimento da cronologia e quanto à proveniência dos muitos tipos conhecidos, de modo que podemos entrar agora numa segunda fase, a da consolidação das cronologias e a determinação dos centros de produção e das vias de difusão. Não é o início que geralmente ainda está por descobrir, mas especialmente o termo da produção dos diferentes tipos.

Com estas duas obras estamos exactamente confrontados com dois estudos que abrangem estes problemas, aliás sem analisar a fundo os vários fabricos de «paredes finas» encontrados e, por isso, com êxito variável. As pastas utilizadas e as características técnicas não parecem ter cativado o interesse específico dos autores. Na primeira obra, há um estudo puramente formal que documenta as formas além dos tipos de decoração e dos engobos, enquanto a segunda aborda este tema - da composição das pastas e características técnicas dos fabricos-pela primeira vez por não dispor de outra informação indicativa sobre as peças das escavações antigas. Por falta de estratigrafía documentada e também por o material estar muito esmigalhado, a autora não encontrou outra hipótese a não ser a classificação dos fragmentos à base das suas pastas. Tenta, então, formular as características dos vários fabricos encontrados. Foi-lhe possível definir três tipos globais, que descreve inicialmente ao tratar dos restos da forma Mayet III. Aí sugere que representam as produções italianas, ibéricas e locais (p. 20). De destacar é a observação que a pasta de várias peças, por exemplo das formas Mayet VIII (p. 20), XIV (p. 25) e XXI (p. 29), apresentam "muitas similitudes com a cerâmica gris ampuritana". Eventualmente chega à conclusão que apenas cerca de $3 \%$ de todas as «paredes finas» encontradas em Badalona são de produção local (p. 34). Nesta produção de Badalona a autora consegue reconhecer imitações das formas Mayet XVIII e XIX, além de dez formas únicas. As últimas são um testemunho da evolução avançada das olarias catalãs (p. 38).

O Ricci (A.) em Atlante delle forme ceramiche II; Ceramica fine Romana nel Bacino Mediterraneo. (Tarde ellenismo e primo impero), Roma, 1985, pp. 232-381.

Conimbriga, 31 (1992), 189-211 
Por causa da grande fragmentação do material, Puerta i López não conseguiu diferenciar os vários tipos e, por conseguinte, junta os fragmentos das formas baixas (Mayet XVIII com XIX) e das formas altas (Mayet XXXVII com XXXVIII) (p. 39). Consequentemente, oblitera qualquer diferenciação que possa ser verificada no futuro, o que achamos inoportuno: afinal, trata-se de formas nitidamente diferentes.

Foi então forçada - felizmente, a nosso ver - a agrupar os fragmentos (192 exemplares) dos tipos XVIII/XIX e XXXVII/XXXVIII, baseando-se nas suas pastas e, portante nos seus fabricos. Foi-lhe possível definir, mais uma vez, três grupos diferentes e sugerir que representam olarias de vários locais, inclusive do vale do Ebro já documentadas por Beltrán (p. 39). Teria sido muito vantajoso se a autora tivesse oferecido uma descrição mais pormenorizada das pastas, incluindo os elementos não plásticos encontrados e uma definição das cores (por exemplo, na escala de Munsell).

López Mullor, por seu turno, depois de uma exaustiva elaboração sobre a evolução e bibliografia do estudo da cerâmica de "paredes finas», segue com a definição da tipologia formal e a classificação dos motivos decorativos.

Também estes motivos foram sujeitos a uma tipologia, elaborada pelo autor e que nos parece ser simples, todavia bastante completa. Porém, López não nos fornece desenhos amostras ou referências aos vasos com a decoração em questão, o que nada facilita a classificação de qualquer motivo por nós encontrado. Além disso, nem sempre dá a classificação dos motivos no catálogo das peças publicadas; assim restam algumas dúvidas. Por exemplo, perguntamo-nos qual será o $\mathrm{n}^{\mathrm{Q}}$ do motivo do vaso na Est.63-4 e vários outros semelhantes; dos fragmentos nas estampas 80-9, 108-2 e 3, ou dos vasos ilustrados na estampa 112-2 e 3? Até ter uma publicação que mostre os motivos com a respectiva numeração parece-nos mais indicado continuar a referir-se à terminologia habitual, eventualmente em conjunto com a tipologia de López Mullor.

O estudo de todo o material proveniente da Cataluña disponível nos museus e de escavações recentes - as últimas especialmente importantes porque proporcionou os achados de, ao menos, uma dúzia de estações - permitiu estabelecer e comparar as respectivas cronologias indicadas para os diversos tipos e fabricos. Além disso, o autor consegue definir peças de produção local entre os demais exemplares tradicionalmente designados de fabrico bético ou das ilhas Baleares. Também alarga a tipologia de Mayet para os produtos ibéricos e de Marabini Moevs para os itálicos. São definidos mais dezassete tipos até agora ainda inéditos (formas LIV a LXX, na sua maioria de produção catalã), além de duas dúzias de peças únicas de formas desconhecidas.

O grande valor do livro de López Mullor reside no capítulo «Conclusiones 1, La Cerámica» em que o autor apresenta um dissertação, mais uma vez exaustiva, sobre cada forma. Nele apresenta algumas observações dispersas sobre a(s) pasta(s) e acabamento(s) encontrado(s), descreve a forma stricto sensu com a sua possível decoração, os fabricos diferentes quando aplicável, além da difusão, cronologia e bibliografia.

Conimbriga, 31 (1992), 189-211 
Infelizmente, também aqui encontrámos uma falha considerável na falta de informação pormenorizada sobre as pastas utilizadas, sobre as quantidades, o tamanho e tipo dos componentes não plásticos dos barros. A informação oferecida é, geralmente, pouco específica ou mesmo ausente e inutiliza, em parte, a possibilidade de usar o livro como obra de referência para tentar localizar a origem de qualquer peça em estudo. A nosso ver, qualquer vaso de qualquer tipo de cerâmica se caracteriza e define melhor pela sua pasta, necessariamente do local, enquanto que a forma e/ou a decoração, muitas vezes sob influência estrangeira, completa o total do seu fabrico.

De especial interesse são os jarros e as bilhas dos tipos LVII a LXIII (pp. 429-436) do século I a.C. até aos meados do século I d.C.

López Mullor inclui os «potinhos alentejanos» (pp. 439-440, forma LXVII) de cerâmica cinzenta e com decoração impressa na gama de «paredes finas», o que se nos afigura forçado. A pasta não parece aquela das outras produções de "paredes finas»; trata-se, decerto, de uma pasta de cerâmica comum típica do Alentejo, todavia de classificação «fina» ou até «média», como acontece bastantes vezes. Já formulámos a hipótese de terem existido dois centros de produção desta gama de «cerâmica cinzenta fina» ( ${ }^{3}$ ); nesse caso teríamos necessidade de admitir igualmente dois centros de produção de «paredes finas» no Alentejo. Parece que o autor não teve ao seu alcance a nossa publicação do espólio da necrópole de Santo André e, por isso, a cronologia que sugere para estes «potinhos» é restrita demais.

É de lastimar que o aspecto gráfico seja tão pobre: o texto está apresentado em fotocópia reduzida do original computorizado. A sua leitura é não só difícil, mas especialmente cansativa, o que prejudica a sua consulta em pormenor. Também é pena a falta de legendas nas estampas, obrigando o leitor a procurar, primeiro, numa lista das estampas e, depois, no próprio catálogo para obter a informação básica de cada peça ilustrada. Além disso, dado que os desenhos nas estampas do volume II não obedecem a uma ordem formal, nem do catálogo, nem da proveniência, torna-se quase impossível chegar a uma conclusão quanto às variações que um tipo pode mostrar, ou, em contrapartida, fazer uma comparação adequada dos pormenores subtis entre o mesmo tipo dos vários centros de produção.

Em suma, a obra constitui um estudo minucioso e completo das «paredes finas» não só da Catalunha, mas também da toda a produção ibérica. Trata-se de uma obra importante e de vanguarda que, infelizmente, é de difícil consulta devido à sua organização formal e apresentação gráfica.

JEANNETTE U. S. NOLEN

(3) Nolen (Jeannette U. Smit), «A cerâmica comum» em: História de Portugal, dos tempos pré-históricos aos nossos dias, João Medina ed., vol. II, A Idade do Ferro e a ocupação romana, pp. 288-298.

Conimbriga, 31 (1992), 189-211 